\title{
LA VIDA CONSAGRADA ANTINOMIAS Y EXPECTATIVAS
}

Autor: Juan González Anleo. Profesor de Sociología de la Universidad Pontificia de Salamanca.
En una sociedad en la que el baile de valores nos desconcierta, el carisma ha pasado a la clandestinidad, las exigencias de la vida religiosa están ausentes de la cultura juvenil, es preciso mostrar claramente los rasgos de la VC, la utopía, para recuperar el potencial de atracción.

En nuestra sociedad española, secularizada y bastante anómica, con un baile de valores que desconcierta al más aplomado y tranquilo, con una Iglesia bien batida por las olas de la crítica interna y externa, por no pocos escándalos o pretendidos escándalos, y con una imagen pública poco atractiva, amén de un clero envejecido y de notable precariedad vocacional, hay, a pesar de todo eso, cantera de vocaciones. Llamo "cantera vocacional" a esos 360.000 jóvenes que en 1999 habían pensado alguna vez en la vida religiosa o sacerdotal como una posibilidad para sus vidas, y a los 30.772 que habían considerado esa posibilidad "a menudo". Estas cifras son sólo una conversión bienintencionada a números absolutos de los porcentajes que nos ofreció la investigación "Jóvenes españoles 99" de la Fundación Santa María, y que analicé detenidamente en un artículo aparecido en la revista Todos Uno1.

1 Juan González-Anleo: "Los jóvenes españoles y a la irrelevancia del proyecto vocacional”, Todos Uno, octubre-diciembre 1999, págs. 29 y ss. 
Esa cantera distaba mucho de ser homogénea. Había más chicas que chicos, más jóvenes de clases media, media baja sobre todo, que de clase alta o de clase trabajadora, y algo más en Andalucía y Castilla y León que en el resto de las CCAA, dejando al margen las Comunidades con muestras demasiado pequeñas para que sus resultados fueran enteramente fiables. Lógicamente en el grupo juvenil de católicos practicantes los porcentajes de quienes habían pensado alguna vez o a menudo en la vida religiosa o sacerdotal era notablemente más elevado: $16,2 \%$ y $1,1 \%$.

Esta cantera vocacional, afirman Julián López y $\mathrm{M}^{\mathrm{a}}$ Begoña de Isusi ha sido poco explotada en los últimos 25 años: " La vida religiosa ha estado ocupada por el problema de su identidad y renovación interna, y al mismo tiempo ha estado comprometida en gran número de tareas evangelizadoras, con entrega admirable, y de hecho, en términos generales y con las debidas excepciones, muchos institutos religiosos, al carecer también de vocaciones jóvenes, no han sabido o no han podido crear y poner en práctica una pastoral nueva con los adolescentes y los jóvenes." La conclusión es muy dura:

"Los datos manifiestan que bastantes congregaciones se comportan como si no fueran conscientes de lo que supone la carestía de vocaciones (...) Suele ser una minoría del $20 \%$, que oscila hasta el 35\%, los que son conscientes de la necesidad de esta pastoral y desean trabajar en ella poniendo medios concretos, como dedicar más personas y planificar bien una pastoral juvenil-vocacional, adaptada a la juventud actual. El resto, un $80 \%$, opta por las siguientes posturas inadecuadas: pasividad (...), inadaptación (....) espera (...). Y la vida religiosa, al menos en muchas congregaciones, ha vivido su carisma en una especie de clandestinidad, sin darlo a conocer y sin ofrecer a los/las jóvenes el ideal de participar en él". ${ }^{3}$

La clandestinidad del carisma puede ser una razón verosímil de la débil eficacia de la pastoral vocacional juvenil. El problema es que

2 Julián López y $\mathbf{M}^{\mathrm{a}}$ Begoña de Isusi, "Realidad actual de la vida religiosa. Datos fundamentales de su vida y de su misión", en Unión de Superiores Generales: Carismas de la Iglesia para el mundo. La vida consagrada hoy, Madrid, Paulinas, 1995, $2^{\mathrm{a}}$ ed., pág. 124-27.

${ }^{3}$ Ibid. Pág. 125. 
el carisma de una congregación o del sacerdocio no se hace patente, clamoroso (todo carisma es clamoroso, aunque no lo pretenda, aunque quizás su publicidad disguste a sus portadores) sino a través del hombre o de los hombres que lo han recibido para la salvación y la prosperidad del pueblo. En esta misma o parecida línea, Javier Elzo sugiere que" la figura del sacerdote, así como la de los religiosos y religiosas, no es percibida por los jóvenes como modelos a imitar. (...) El sacerdote ocupa uno de los lugares más bajos de la escala social. Me temo, además, que esto es consecuencia de algo no previsto como decisión voluntaria, el menos durante unos años, como si de una búsqueda de minusvaloración se tratara, una huída de toda notoriedad, un deseo de equiparación (y dilución) en los fieles, especialmente en los más menesterosos. (...), un rechazo radical de la idea de poder ser líder (se podrá ser acompañante, a los más, animador)..."4

Desde el panorama norteamericano, y bastante antes del doloroso escándalo que ha sacudido a la iglesia católica en ese país,, escribía el sociólogo Greeley:

"Desgraciadamente, quizás debido a una pobre comunicación con los laicos, los sacerdotes no parecen tener mucha confianza en la importancia de su propio ministerio como tenían en los años anteriores al II Concilio Vaticano. Y como consecuencia de esta falta de convicción en su propia importancia y en la futura importancia de su misión, no se muestran inclinados a invitar a los jóvenes a seguirles en su camino. El declive se ha operado no en la importancia del ministerio sacerdotal, como pudiera parecer, sino en la percepción que tienen los sacerdotes de la importancia de su propio ministerio". 5

Esa falta de convicción está relacionada con los "malestares" de la vida religiosa que comenta Pier Giordano Cabra 6. Malestar cultu$\mathrm{ral}$ al no entender lo que está ocurriendo en el cambiante mundo actual y no poder dar claramente respuestas adecuadas; malestar apostólico derivado del hecho de que algunas (o muchas) obras apostólicas en las que se han trabajado ya no son tan florecientes como en otros tiempos,

\footnotetext{
4 Jóvenes españoles 99, Madrid, Fundación Santa María, 1999, pág. 302-03.

5 Andrew Greeley: The Catholic Myth. The Behaviour and Beliefs of Americamn Catholics, New York, Simon and Schuster, 1997 pág. 221.

6 Pier Giordano Cabra: La vida religiosa en misión, Santander, Sal Terrae, 1989, págs. 111 y ss.
} 
y malestar de la incredulidad "que surge a veces como un muro impenetrable que hace irrelevante el mismo lenguaje religioso y que produce la sensación de ser impotentes y de estar inermes".

Es cierto que muchos no seguirían esa invitación aunque fueran invitados porque, entre otras dificultades, los jóvenes difícilmente aceptan hoy la modelización de un estilo prefijado de vida, de un Código, una Regla o un Reglamento, y pretenden, a veces lo consiguen, trazar con mano segura su propio estilo y propia trayectoria vital, aunque de forma a menudo inconsciente se inspiran en modelos vivos y sugerentes, hombres y mujeres que conocen personalmente o por los MCM, y ante los que experimentan un deseo de "parecerse a", de compartir sus experiencias vitales, de penetrar su "misterio".

En la cantera han aparecido otros competidores. Los recuerda Abbruzzese cuando habla del nacimiento de una misionaridad laica ("misionaritá laica") de trabajadores sociales, psicólogos, psicoanalistas, médicos... -a los que habría que añadir ahora los expertos y profesionales de las ONG- que reivindican una competencia propia, casi exclusiva, en todos los ámbitos sociales de transformación de las condiciones de vida del hombre y del mismo hombre, donde han trabajado durante siglos los hombres y mujeres de la VC.7

Pero si la cantera vocacional, aunque muy solicitada, se encuentra poco explotada por los agentes vocacionales de la $\mathrm{VC}$, una razón más plausible puede ser, a mi juicio, la falta de pericia de los nuevos canteros o picapedreros de la vida consagrada. Es probable que esta falta de pericia obedezca a un cierto desfase generacional, a la ausencia de una generación de sacerdotes y religiosos que se secularizaron y que no fueron reemplazados en su momento por una generación joven de consagrados, más próximos y más en contacto con los adolescentes y jóvenes "vocacionables". Pero la razón más convincente de la infraexplotación de la cantera es, sobre todo, que han aparecido en ella fallas y quiebras de difícil acceso y explotación. De esas fallas y quiebras trata mi colaboración en este número de la revista.

7 Salvatore Abbruzzese: La vita religiosa. Per una sociología della vita consacrata, Milán, Paolinas, 1995, pág. 275 


\section{Exigencias de la vida consagrada y cultura juvenil}

Desde una perspectiva no condicionada ni por la Teología ni por el Derecho Canónico, hablar de "exigencias" de la vida consagrada puede ser, probablemente, una aventura poco aconsejable. Las Ciencias sociales que podrían ocuparse del tema no suelen, no deben, atreverse a fijar requisitos. Su vocación es la de estudiar y analizar hechos, y darles la explicación más fiel y verosímil, más consonante con la realidad y con las teorías bien consensuadas. Pero las Ciencias Sociales, especialmente las que se interesan por las organizaciones, su buena marcha, sus éxitos y sus fracasos, suelen ocuparse de las cualidades "ideales" de los líderes y de los miembros, de los rasgos de personalidad que son necesarios para desempeñar adecuada y eficazmente roles en la organización.

Desde esta modesta perspectivas trataré las antinomias siguientes8:

1. Compromiso estable frente a Identidad flexible y abierta.

2. Fortaleza y Magnanimidad frente a Generación Blanda y Consentida.

3. Apertura activa a los demás frente a autismo social narcisista.

4. Acción social fecunda frente a Pasotismo.

5. Gratuidad frente a Utilitarismo consumista.

6. Solidaridad combativa frente a Individualismo egoísta.

7. Religiosidad profunda frente a alejamiento de la religión.

8. Optimismo vital frente a desconfianza pesimista en el futuro.

9. Identificación con la Iglesia frente a a-clesialidad.

1. La capacidad de compromiso, y de compromiso profundo, si no radical, parece una cualidad absolutamente requerida para un

${ }^{8}$ En su estudio de 1961, ya clásico, "Religión como una ocupación", Joseph Fichter analiza detenidamente las cualidades iniciales de los sacerdotes, religiosas y religiosos. No examina los requisitos oficiales, pero del examen de los datos va extrayendo de aquí y acullá rasgos de personalidad y de comportamiento "normales" de los jóvenes que ingresan en los Seminarios y Noviciados. Entre esos rasgos "normales", comenta el compromiso, la madurez, la generosidad, la lealtad, una piedad sobresaliente, la docilidad...Han pasado cuarenta años desde la publicación de su trabajo, pero muchas de sus ideas conservan su validez. (Joseph Fichter: Religión as an Occupation, University of Notre Dame Press, 1961. El libro de Herveé Carrier "La Vocación" sólo muy indirectamente habla de los requisitos al tratar el problema de las exigencias de la vida sacerdotal (Herveé Carrier, La vocación, Dinamismos psicosociológicos, Bilbao, Mensajero, 1970, págs. 167-69. 
proyecto serio de vida consagrada Los sociólogos entienden por "compromiso" una obligación interiorizada por el sujeto de seguir un itinerario singular de acción para conseguir un objetivo particular, con una consecuencia clave: se limita la libertad de elección y se reduce el número de alternativas abiertas a ese sujeto. En el contexto de la vida consagrada se reducen permanentemente, en principio, tanto la libertad de elección como el número de alternativas abiertas al joven comprometido.

El consagrado, el "virtuoso religioso", como suelen decir los estudiosos italianos, acepta en virtud de su compromiso pertenecer con mayor o menor firmeza a lo que la Sociología denominó, con feliz expresión, las "instituciones codiciosas". Coser las describe asíp: exigen de sus miembro una lealtad exclusiva, y para ello se esfuerzan por reducir la demanda de roles competitivos y de posiciones de status en cuanto pueden afectar a sus miembros, a los que se desea mantener recluidos en los confines de la institución Los rasgos de estas instituciones, uno de cuyos ejemplos, dice Coser, son los jesuitas, son éstos: la pertenencia es voluntaria, ejercen presión sobre sus miembros para que corten o reduzcan sus relaciones con otras instituciones o personas que puedan hacer demandas competitivas, inhabilitan a sus miembros para otras actividades distintas a las pretendidas por la institución -mediante promesas, juramentos o votos, en el mejor de los casos-, controlan la vida sexual de sus miembros en cuanto constituye amenaza para una lealtad sin divisiones a la institución...

No sería quizás difícil conseguir que un buen puñado de jóvenes españoles interiorizaran una adhesión sentimental a un objetivo, a una misión tan noble y elevada, en principio, como la de la vida consagrada -primera parte de la definición de compromiso-. El gran escollo emerge cuando -segunda y espinosa parte de la definición- el joven se encara con "las limitaciones" en su libertad de elección y en las alternativas abiertas al sujeto, García Roca lo ha explicado muy bien en su ensayo sobre los valores de los jóvenes. ${ }^{10}$ Las señas tradicionales de la

9 Juan González-Anleo: Para comprender la Sociología, Estella, Verbo Divino, 199, págs. 193-94.

10 Joaquín García Roca: Constelaciones de jóvenes, Barcelona, Cristianisme i Justicia, 1994, págs. 27-31. 
identidad personal se ven alteradas, la identidad es hoy abierta y se configura así una nueva constelación de valores del individuo con el énfasis puesto en la diferenciación, la movilidad, la diversidad de identidades, el reconocimiento social y moral en todos los rincones de la existencia, la flexibilidad frente a la obligación, el derecho a la diferencia, la misma solidaridad pero abierta... Comprometerse de manera estable con una institución, pienso yo, supondría una renuncia a buena parte de esos valores y aceptar recortes y limitaciones en esa movilidad, apertura y flexibilidad.

Subyace a esta casi invencible impotencia ante el compromiso, incluso el mero comprender su significado y nobleza, la no percepción de la deuda que la generación actual tiene contraída con la anterior y con la que le sucederá en la escena social, en relación con el bienestar económico y social que ha recibido de aquella, y la obligación moral de trasmitírselo acrecentado a ésta. Y en dudoso caso de percibirla, el rechazo categórico de la misma. Yankelovitch lo ha entendido bien: por el mero hecho de vivir en una sociedad próspera y segura, el joven se siente con derecho a poseer y disfrutar de lo que tiene delante, según el siguiente falaz silogismo: está ahí, tengo deseo de poseerlo, luego tengo derecho a ello. En una palabra, el deseo como fuente de derechos. Sin obligaciones de ninguna índole. Y, por lo tanto, sin compromisos.

2. La fortaleza y la magnanimidad son virtudes necesarias para todo compromiso radical, como el exigido en la vida consagrada. La VC es difícil, lo reconocía André Malraux en una predicción sorprendente dada su bien conocida ideología: "Sólo Dios conoce las pruebas que El impondrá al sacerdocio, pero yo creo que es necesario que el sacerdocio vuelva a ser dificil" 11 . La vocación a la vida consagrada implica una fuerte tensión de fuerzas que pugnan por salir y expresarse en la vida y algo que se retrae ante el paso decisivo. Y toda opción exige muchas renuncias a posibilidades que se veían cercanas.. "Una opción se enuncia en forma positiva, ya que se escoge libremente un camino, pero no hay dificultad alguna en admitir realistamente que implica muertes. Quien elige (...) ser médico renuncia -aunque no lo

11 Citado por F. Boulard, Essor ou Declin du Clergé Français, Paris, Cerf, 1950, pág. 344. 
pronuncie o escriba ante notario- a ser abogado, militar, sacerdote, filósofo, etc. Es mayor la renuncia que la opción".12

El problema es que la fortaleza y la magnanimidad no están de moda en el repertorio de virtudes del hombre joven, que vive en una sociedad "blanda" de pensamiento "débil". Lo reconocía Andrés Orizo en su análisis de la II Encuesta Europea de Valores. Y en ese mismo análisis resaltaba el escaso valor que los padres conceden hoy en España a las cualidades o virtudes fuertes en la educación de sus hijos. Que lo están pagando muy caro cuando en su lucha sin cuartel contra una estructura socio-económica de falta de empleos, trabajos "basura", contratos precarios e inaccesibilidad de la vivienda, necesitarían toda la fortaleza y perseverancia del mundo. Valores o virtudes como la abnegación, el sacrificio y el trabajo duro apenas se cotizan en la "bolsa" de la socialización de niños y adolescentes españoles.

En la Encuesta Europea de Valores del 2.000 las cuatro cualidades más valoradas por los españoles para inculcar a los niños fueron los "buenos modales", "el sentido de responsabilidad", la "tolerancia y respeto a los demás" y la "obediencia", virtudes orientadas al orden social y al reconocimiento social fueron preferidas por una media del $75 \%$ de respondentes. Las cuatro últimas, las menos favorecidas, fueron la "determinación y perseverancia, a las que se refirieron el $27 \%$ "el "trabajo duro", mencionado por un $21 \%$ la "fe religiosa", mencionada por un $20 \%$, y la "abnegación", mencionada por un $2 \% .{ }^{13} \mathrm{La}$ Moral clásica diría: se encarece la virtud de la prudencia, se desvaloriza la virtud de la fortaleza. Amando de Miguel llega a hablar de los jóvenes españoles como "una generación de consentidos y de mimados": "pagas" semanales generosas, ropa de marca, largas horas nocturnas fuera de casa, consumo exuberante, clases de ballet, de Informática, de inglés, vacaciones en el extranjero para aprender idiomas... Es difícil decirles que NO. Y cuando a un chico nunca los padres le dicen "NO" difícilmente se incorpora al bagaje vital del niño y del joven la fortaleza necesaria para enfrentarse con la vida y con los gran-

12 J. Manuel Cordobés: voz "Vocación" en Diccionario de espiritualidad, dir. por Stefano de Fiores y Tullo Goffi, Madrid, Paulinas, 1983, págs. 1424-25.

13 Carmen Valdivia: "La Familia", en España 2.000.Entre el localismo y la globalización, Madrid, Fundación Santa María-Universidad de Deusto, 2.000, págs. 144-145. 
des compromisos. Eso afirman, al menos, los entendidos en educación infantil y juvenil.

La necesaria disciplina interior exige el dominio personal de lo puramente instintivo y experiencial, la capacidad para aceptar normas que no proceden de uno mismo, la superación de una ética puramente "situacionista" y del relativismo. Pero los jóvenes afirman candorosamente que sólo aceptan las normas basadas en experiencias y deseos personales. Sería necesario analizar cómo se construyen esas normas, hasta qué punto están libres de influencias e injerencias, y en qué medida les influyen los Medios de Comunicación de Masas, la calle, y, sobre todo, los amigos. Sea cual sea la autonomía real de los jóvenes y la "pureza" de origen de sus normas personales, la actitud original y profunda de rechazo a la heteronomía aparece claramente en todas las investigaciones sobre el tema, especialmente cuando se trata del espacio privado juvenil: amigos, vida sexual, relaciones,...

El problema de fondo no consiste tanto en la pretensión juvenil de autonomía, de emancipación e independencia normativas, sino en que esta presunta autonomía está fundada, o mejor, dicho, se tambalea sobre un suelo frágil y traidor de relativismo axiológico. Los jóvenes como recuerda Peter Berger en una simpática metáfora, se han "asomado al jardín del vecino de al lado" y han visto cosas muy diferentes a las de su propio ámbito. Los jóvenes viajan fuera de España más que nunca -turismo, convivencias internacionales, cursos de inglés o de francés, becas Erasmus...-, y ahora hay que contar además con Internet, el enorme y caótico ventanal abierto al mundo entero, del que aprovechan sobre todo los jóvenes. Y los "filtros" clásicos que antes cribaban y seleccionaban el aluvión de información -la familia, la escuela, la iglesia...- han perdido su presencia y su influencia.

El relativismo axiológico juvenil, por descontado, no puede cimentar ni cobijar normas sólidas, abandonadas ahora a la intemperie. Se patentiza en las declaraciones juveniles sobre el Bien y el Mal, y en el notable nivel de permisividad ética, el más alto de las juventudes europeas. Reléanse las páginas que el Informe "Jóvenes españoles 99" de la Fundación Santa Maria dedica al tema de la permisividad. ${ }^{14}$ A pro-

14 Francisco Andrés Orizo: "Jóvenes, sociedad e instituciones", en Jóvenes españoles 99, Madrid, Fundación Santa María, 1999, págs. 83-90 
pósito de la distinción básica y fundante entre el Bien y el Mal, -el último dato procede del estudio del 2.000 sobre los valores en Españael $61 \%$ de los jóvenes, $65 \%$ si son universitarios, muestran su acuerdo total con la alternativa: "No puede haber nunca líneas directrices absolutamente claras sobre lo que es el bien y el mal. Lo que está bien y está mal depende completamente de las circunstancias del momento". ${ }^{15}$

3. La apertura a los demás es una condición necesaria para hacer posible una respuesta o acogida que dé cumplimiento a la vocación. Una apertura amplia y generosa, pues la vocación a la vida consagrada es un carisma que se recibe para el bien y utilidad de los demás. Es pura teología de San Pablo en la Primera a los Corintios, y es la idea de Max Weber el sociólogo que incorporó brillantemente el término a la Sociología. El gran enemigo, o mejor, la gran legión de enemigos de este requisito para la vocación a la vida consagrada, son el individualismo, el egoísmo y egocentrismo, que destruyen toda posible sensibilidad para la donación. ${ }^{16} \mathrm{El}$ individualismo juvenil es de un tipo particularmente peligroso, un híbrido del individualismo utilitarista, pragmático, en el que influye el consumismo atroz de la actual sociedad, marca de identidad "reclamada" por los mismos jóvenes, y del individualismo expresivo y permisivo, que caracteriza hoy por hoy a la sociedad occidental. La juventud española, hay que insistir, es la más permisiva de Europa, al menos en sus actitudes y opiniones sobre la justificación de comportamientos "desviados", como la droga, la libertad sexual premarital, el alcohol, el aborto, las aventuras extraconyugales, la prostitución, etc. En medida variable esas actitudes y opiniones se traducen luego en comportamientos y en hechos. Pero esto es otro cantar, que se escucha con frecuencia en las calles y noches de España, y cuyo eco llega en ocasiones a los hospitales de urgencia y las comisarías.

Los jóvenes españoles están muy "abiertos" a los "otros"... con tal que esos "otros" sean sus amigos, su grupo, su pandilla, su banda, y con tal que sea para "pasarlo bien", para "vivir a tope". Pero a la hora

15 España 2.000. Entre el localismo y la globalización, Madrid, Fundación Santa María, 2000, pág. 36.

16 J.M. Cordobés, op. cit. Pág. 1425. 
de trabajar juntos para los demás, se muestran bastante cerrados a las asociaciones, grupos benéficos y $\mathrm{ONG}$, aunque simpaticen con ellas. Un 70\% de jóvenes no pertenecen a ninguna asociación, el 30\% restante lo hacen a grupos regionales o locales, a asociaciones deportivas, a grupos religiosos y a grupos culturales y educativos. Los grandes movimientos sociales que hoy suscitan fervor y entusiasta aprobación en el mundo juvenil -pacifismo, ecologismo, defensa de los Derechos Humanos, ayuda al Tercer Mundo...- reúnen entre todos un magro 6\% de jóvenes españoles. Es "el espacio poco usado", en feliz expresión de González Blasco en Jóvenes españoles 99.17

Se puede por añadidura hablar de un alarmante síndrome de narcisismo juvenil, estrechamente relacionado con el autismo social ya mencionado. El joven vive centrado en su grupo, obsesionado por su bienestar psíquico y físico, reacio por ello a compromisos que lo saquen de su "guarida " psicológica (Leawitt), a que le causen preocupaciones, a que le impongan obligaciones.

Estrechamente relacionado con el narcisismo ha destacado García Roca el culto al cuerpo como una de las grandes constelaciones de valores de los jóvenes españoles hoy. La centralidad del cuerpo en el universo juvenil es una realidad indiscutible. El cuerpo influye de una manera decisiva sobre la nueva sensibilidad, el imaginario y las prácticas cotidianas de los jóvenes. Y se ha convertido en objeto de atención y de superación, de ahí las actividades para cuidar ese capital que hay que apropiarse y optimizar: los gimnasios, los cuidados higiénicos y cosméticos del cuerpo, los deportes "autistas" y narcisistas como el: "footing" y bicicleta estática. Han cambiado las finalidades y objetivos del deporte entre los jóvenes y bastantes hombres maduros: del deporte como agente de regeneración moral y con vistas al desarrollo del esfuerzo, la lealtad y el sentido de equipo, al deporte como espacio de trabajo, para experimentar sensaciones fuertes, sentirse a gusto consigo mismo y, desde luego, como diversión.

La salvación del cuerpo -la salud, la fitness y la belleza corporalha reemplazado en muchos jóvenes a la salvación del alma. Sólo así se

17 Pedro González Blasco: "Relaciones sociales y espacios vivenciales" en Jóvenes españoles 99, Madrid, Fundación Santa Maria, 1999, págs. 241-43. 
explican los sacrificios que los jóvenes realizan para alcanzar y mantener esa salud, fitness y belleza. Un diario nacional relataba hace unos días que un $28 \%$ de los adolescentes madrileños de 15 y 16 años hace dieta porque cree sufrir sobrepeso, un $8 \%$ no ha comido durante 24 horas con el fin de perder peso, un $6 \%$ ha llegado a provocarse un vómito con la misma intención y un $4 \%$ ha ingerido píldoras adelgazantes. ${ }^{18}$ No hay que perder de vista, afirma García Roca en el estudio citado, que los jóvenes tienen una visión del cuerpo más integral que la que antes predominaba en el mundo occidental por influencia del platonismo y del Cristianismo. Atribuyen así al cuerpo cualidades y atributos que antes "pertenecían" sólo al alma o a la persona, como los atentados contra la dignidad del cuerpo/alma, los malos tratos, físicos o mentales, la pena de muerte, la mercantilización de órganos, etc. La centralidad del cuerpo nos brinda es una oportunidad histórica de reencontrar el lugar para recuperar el espíritu, haciendo que el cuerpo, sin dejar de ser cuerpo, se vuelva alma. Quizás desde esta perspectiva pueda recobrarse también un sentido integral y exultante de la castidad en la vida consagrada. En un pliego importante de "Vida Nueva", Cosme Puerto relata algunos de los significados más relevantes de la "sexualidad célibe": los célibes como mensajeros de libertad sexual en un mundo de adictos genitales, como testigos en el mundo de hoy de la ternura del amor no posesivo de Dios; la sexualidad célibe como dinamismo realizador de la personalidad célibe, como una forma más de relación interpersonal y de comunión con el otro, como un camino de amor oblativo y gratuito y como camino privilegiado de superar la soledad, ya que es creadora de comunidad...19

4. La victoria sobre el pasotismo es una condición necesaria para la acción comprometida y fecunda que implica toda vida consagrada. Antes he mencionado el handicap que para la pastoral vocacional representa el desinterés, mezclado con una cierta resignación e incluso fatalismo, de muchos sacerdotes y religiosos, falsamente convencidos de la falta de su propia importancia y de la importancia de su misión (Gree-

${ }^{18}$ El País, 27 enero, 2003, sobre una encuesta de la Consejería de Salud.

${ }^{19}$ Cosme Puerto, O.P, sexólogo: "Sexualidad y Celibato ", en Vida Nueva, 2.336, 6 julio 2002, pág.30 
ley). Esos sacerdotes y religiosos pueden llegar a convertirse en cierta forma en los "consagrados pasotas", que "pasan" de todo tipo de pastorales vocacionales o, simplemente, de propuestas de vocación y misión a los jóvenes con los que tienen contacto frecuente. Pero lo que ahora nos interesa es el problema, no tanto de los pasotas sino del pasotismo como síndrome de la apatía, pasividad e indiferencia del mundo juvenil ante todo lo que signifique y exija salir de la confortable y mullida "guarida" en la que viven y en la que quieren seguir viviendo.

En la galería de tipos juveniles predominantes a mediados de los 90, Javier Elzo cifraba en una 10\% la proporción de "pasotas" que pululaban por los espacios juveniles. Pero el pasotismo, aunque sea no como tipo juvenil puro, forma ya parte del bagaje psico-social de los jóvenes. Los pasotas, así se presentan en los análisis sociológicos, son vividores, partidarios de la moral de la diversión frente a la moral del deber, tienden a sacralizar el pasarlo bien y la movida permanente, se muestran alérgicos a todo lo que signifique altruismo, a toda movilización para alguna causa mínimamente trascendente, a todo proyecto humano o social. Abundan entre ellos los indiferentes en materia religiosa, los agnósticos y ateos, que "pasan" del sentido de las cosas y de las perennes cuestiones existenciales.

En el universo juvenil español representan un $10 \%$, pero la absoluta apatía política o sindical 20 y el vivir de espaldas a una religiosidad seria -hallazgos constantes de todas las investigaciones y encuestas sobre la sociedad española-, son ya parte importante de la herencia que ha recibido el joven español de una generación de padres demasiado preocupados con el sacar adelante la transición política, o con el mero y noble defenderse y defender a la familia de la precariedad laboral y la inseguridad económica, o con el éxito socio-económico personal.

$\mathrm{El}$ argumento no expresado que subyace a este pasotismo es elemental, pero quizás difícil de comprender por los que pertenecemos a la generación de los "deberes" y las "lealtades". Reza así: la generación actual es la generación del "me lo merezco", del tengo derecho a

20 En "Jóvenes españoles 99" se puede comprobar esta apatía política y religiosa: sólo un $6 \%$ y un $4 \%$ de jóvenes conceden mucha o bastante importancia a la religión, y a la política, respectivamente, (pág. 59), sólo un $1 \%$ pertenecen a partidos políticos, y otro $1 \%$ a organizaciones sindicales. (pág. 241). 
todo sin contrapartida, y con rechazo de todo tipo de normas y de obligaciones que puedan frenar la búsqueda individual del éxito y del confort. Pascal Bruckner habla con agudeza de las "bodas" del derecho, el consumismo y del Estado de Bienestar, que concurren para engendrar un ser voraz, impaciente por ser feliz en el acto, y convencido, si la felicidad tarda en llegar, de que ha sido vejado y de que tiene derecho a una compensación. Esas bodas han engendrado las epidemias de nuestra época, el infantilismo y el victimismo, fundados ambos sobre el rechazo de la deuda, la negación del deber y la certeza de disponer de un crédito infinito en la sociedad, que es, ella sí, " deudora". Escribe el brillante ensayista francés ${ }^{21}$ :

"Así pues, lo queremos todo y su contrario: que esta sociedad nos proteja sin prohibirnos nada, que nos cobije sin obligaciones, densas redes de una relación afectuosa; resumiendo, que esté ahí para nosotros sin que nosotros estemos ahí para ella".

Retrato robot del pasota: me lo merezco, tengo derecho a todo, no tengo obligación de nada, dejadme en paz vivir mi propia vida.

5. El sentido de gratuidad es un elemento esencial de toda vida consagrada. Se pensó que con el advenimiento del postmaterialismo y del consumismo en las sociedades avanzadas y liberadas, aunque no totalmente, de la precariedad económica y la inseguridad física (las guerras), uno de los beneficios para esas sociedades iba a ser la recuperación del sentido de gratuidad, después de tanta historia de utilitarismo y pragmatismo (Inglehart) No parece que, de momento, haya sido así, aunque la gente hoy esté más interesada por la calidad de vida, la estética de las ciudades, o la libertad de expresión, valores que Inglehart considera postmaterialistas. Una de las razones de la escasa presencia de la gratuidad en la vida actual ha sido que el consumismo desenfrenado ha tomado el relevo del materialismo utilitario y pragmático de los viejos tiempos. Los jóvenes han sido las víctimas predilectas de este consumismo depredador de valores.

El consumismo despilfarrador de nuestras sociedades ha supuesto la liquidación de la ética del trabajo y de la austeridad que caracteriza-

21 Pascal Bruckner: La tentación de la inocencia, Barcelona, Anagrama, 1996, págs.. $109-10$. 
ron al capitalismo fundacional, la afirmación individualista y la realización de una vida concebida como tener y poseer y disfrutar de muchísimas cosas, y poder dar al cuerpo todos sus deseos. Pero lo que más nos interesa aquí y ahora es el riesgo o riesgos que el consumismo representa en la formación de la personalidad de los adolescentes y jóvenes:

- Primer riesgo: una visión cosística y cosificadora de la realidad, en la que todo hace referencia a la utilidad que puedo sacar de los objetos.

- Segundo riesgo: distorsión del sentido de la persona, que acaba por ser percibida sólo a través de la óptica del interés, la utilidad y la satisfacción propia. Visto de otra manera: el otro sólo tiene valor para mí en cuanto poseedor de cosas como la riqueza, la belleza, el sexo, la influencia, el poder, el encanto personal, y otras cualidades físicas y espirituales que pueden procurarme placer y aumento de mi satisfacción vital.

- Tercer riesgo: al difundirse en la sociedad las actitudes descritas en el primer y segundo riesgo se multiplican las relaciones interesadas, estratégicas, calculadoras, orientadas a la satisfacción de los deseos propios.

- Cuarto riesgo: El estilo consumista y positivista glorifica la opulencia, desprecia la austeridad y la sobriedad, hace proliferar relaciones unidimensionales y diplomáticas, y comunicaciones de pura táctica, sin diálogo yo-tú.

Estos cuatro riesgos culminarían en una gravísima clausura del ser humano a la solidaridad y a la gratuidad. Si las relaciones con Dios son medidas a través de esta óptica deformadora y distorsionadora, la fe corre el riesgo -ya sería el quinto riesgo- de transformarse en un juego de relaciones interesadas y mercantiles, donde el Dios que "me amó y se entregó por mî" es un acontecimiento incomprensible y algo embarazoso y ridículo. La llamada de ese Dios a la consagración y a la misión sería no escuchada, y la respuesta del "llamado", algo sumamente improbable.

6. La solidaridad combativa, alimentada por un saludable inconformismo y por un sentirse a disgusto en un mundo plagado de injusticias y crueldades, es sin duda un factor de gran efectividad en la disponibilidad a una llamada especial de Dios para la vida consagrada. 
el núcleo juvenil de los seriamente religiosos el procedimiento más adecuado sería ir trazando círculos concéntricos de vivencias religiosas según su grado de interioridad y autenticidad hasta llegar al grupo "seriamente religioso". Esto es prácticamente imposible con los instrumentos que manejamos los sociólogos, sería precisa la intervención de un maestro en discernimiento de espíritus que entrevistara personalmente a los 5 ó 6 millones de jóvenes españoles de 15 a 24 años. Con las pobres herramientas que tenemos a nuestra disposición se puede intentar, solamente intentar, una aproximación a la identificación de ese núcleo. En el año 1999, y en el último Informe sobre la Juventud Española de la Fundación Santa María se observan las siguientes indicaciones:

- El 35\% de los jóvenes se dicen "católicos practicantes"

- Y el 33\% pueden ser calificados de "católicos autónomos", grupo muy religioso desde el ángulo de sus creencias cristianas, pero, sin ser anticlericales, no se distinguen por su eclesialidad: sólo un $12 \%$ entre ellos creen que para ser considerado persona religiosa es necesario pertenecer a la Iglesia y seguir su doctrina y sus normas.

- Un 27\% aceptan el misterio de la Resurrección, clave de la fe y razón de la esperanza cristianas.

- Puede suponerse lógicamente que ese tercio aproximado de jóvenes-entre el 27 y el $35 \%$ - no constituye todavía el núcleo escogido que buscamos. Es demasiado abultado. Un dato más preciso sustenta esa suposición.

- Sólo un $12 \%$ de jóvenes asisten a Misa todos los domingos y fiestas.

- Finalmente, sólo un 6\% pertenecen a asociaciones de tipo religioso, porcentaje que entre los que se declaran "católicos practicantes" se eleva a un $14,7 \%$.

- Sopesando cuidadosamente todos estos porcentajes puede aventurarse que entre un 5 y un $10 \%$ de jóvenes destacan por un catolicismo serio y comprometido, el núcleo religioso que se quería identificar.

Es posible concluir prudentemente que existe en el universo juvenil español una minoría católica activa de cuya "seriedad religiosa" no hay razones para dudar, aceptando lógicamente excepciones en un 
doble sentido: jóvenes abiertos plenamente a Dios y a sus eventuales llamamientos pero alejados del mundo de los ritos, las prácticas y las doctrinas, y jóvenes de un marcado moralismo, ritualismo y eclesialidad pero de escasa apertura espiritual y pobre solidaridad humana.

La minoría católica activa se puede caracterizar con estos rasgos: mayor integración en la sociedad y sus instituciones, mayor satisfacción con sus estudios, familia y trabajo, mayor tendencia al asociacionismo y al voluntariado, pruebas más palpables de solidaridad, alta valoración de la honradez, posturas menos permisivas en el terreno ético, especialmente en relación con la sexualidad y el respeto a la vida. En una palabra, prefiguran un tipo de hombre de mayor equilibrio afectivo, integración social más pronunciada y nivel más elevado de satisfacción vital. ¿Son realmente así esos jóvenes católicos ?

8. El optimismo ante la vida y el futuro parece una condición de suma conveniencia cuando se piensa en la vida consagrada y en la actividad evangelizadora. Me imagino que no habrán faltado en la historia de la Iglesia santos o, sencillamente, cristianos de gran altura moral y profunda religiosidad, que se han distinguido por su pesimismo, incluso por su desconfianza hacia el futuro. Y no han faltado ni faltan actualmente razones para el pesimismo, últimamente agudizadas por la globalidad, las amenazas de cariz ecológico y la prepotencia opresora de los poderosos de este mundo. Pero el hombre de fe y esperanza cristianas siempre encuentra razones profundas para un prudente optimismo, y para la serenidad y el aliento que su proyecto de vida exigen.

Los jóvenes españoles son presentistas y desconfían obstinadamente del futuro. La cultura del 68 inculcó un fuerte pesimismo ante el futuro, muy poco prometedor, catastrofista incluso, debido a la amenaza pendiente de un holocausto nuclear. Las generaciones actuales siguen viviendo ese pesimismo por otras amenazas menos apocalípticas pero que pueden tocar directamente con sus propias manos: el desempleo, los contratos basura, las drogas, la falta de vivienda, los obstáculos a la deseada emancipación, los pertinaces tambores de la guerra...

El presentismo implica inexorablemente el enfriamiento de las utopías, el triunfo letal del pragmatismo, la alergia a todo sueño de cambiar la sociedad, el desinterés por grupos y asociaciones que persiguen proyectos de largo alcance. Y, como lógica consecuencia, el flo- 
recimiento de un pasotismo blando, templado por la necesidad de estudiar, trabajar, y, de forma muy acusada en España, por el apoyo incondicional y cálido de la familia de origen. Y la vida consagrada tiene mucho que ver con una utopía evangélica prefigurada y simbólicamente realizada en una comunidad de amigos de Jesús. La noche es el símbolo de este presentismo que cercena proyectos serios, compromisos radicales $\mathrm{y}$, hay que repetirlo, utopías intramundanas.

Hemos topado con el concepto de liminalidad. La vida consagrada es fronteriza, afirma José Cristo García Paredes en un trabajo de 1993, " se ubica en un lindero, en un límite, en un sendero entre dos campos, o si queremos se sitúa ante el umbral". Siempre ha tenido en general" una nostalgia del paraíso o del mito de la comunidad con un solo corazón, una sola alma y todo en común, realizada aquí mismo en la tierra". Volveré sobre el tema.26

9. La identificación con la Iglesia católica, no una identificación ciega y muda, sería una cualidad esperable en todo aspirante a la vida consagrada. Aparece aquí uno de los obstáculos más serios para que ese potencial de vida consagrada se actualice y fructifique: la cultura juvenil anti-eclesial de la juventud española. O quizás mejor, cultura a-eclesial. Recordemos que un 33\% de los jóvenes que en la tipología religiosa descrita anteriormente llamábamos "católicos autónomos" son los más profundamente religiosos y éticos del universo juvenil pero afirman que van por libre respecto a la Iglesia, "pasan" en gran medida de su doctrina y de sus normas, son, en expresión del profesor Elzo, a-eclesiales, aunque no anti-eclesiales ni, menos, anticlericales.

En opinión de no pocos teólogos - cito el reciente trabajo de Castillo- el Concilio Vaticano II despertó muchas expectativas sobre los necesarios cambios en la Iglesia, y la gente comenzó a notar en seguida que la Iglesia, de pronto, empezó a ser distinta. Cambiaron señas de identidad seculares como el latín la sotana, el hábito y muchas devociones populares, usos, costumbres y ritos religiosos; algunos curas se casaron o se metieron en política; hubo modificaciones a través del nuevo Derecho Canónico; se oían en los sermones cosas que llamaban la aten-

26 José Cristo Garcia Paredes: "Liminalidad, Frontera, Misión", en 10 Palabras clave sobre Vida Consagrada, Estella, Verbo Divino, 1993, $2^{\text {a }}$ ed., págs. 334-346. 
ción... Los fieles ya no encontraban en la Iglesia la seguridad que siempre habían encontrado. Se produjeron cambios profundos en la Teología, con gran creatividad teológica en los años siguientes al Concilio.

Pero pronto empezó a aumentar el control de Roma y hubo numerosos casos de teólogos destituidos de sus cátedras, lo que inhibió esa creatividad. La teología oficial de la Iglesia permaneció anclada en las posiciones más tradicionales. Y, sobre todo, no cambió la organización eclesiástica, y en especial todo lo relacionado con el poder: quién lo ejerce, con qué estilo se ejerce y se gestiona, cómo se protege el prestigio de la Iglesia, cómo se realiza "de ipso" la famosa "eclesialidad episcopal". Esta ha quedado reducida a "una bella teoría", debido al control ejercido por Roma sobre las Conferencias episcopales, sobre el Sínodo de los obispos y, en especial,sobre el nombramiento de los obispos con vistas a configurar un episcopado en el que lo más pretendido es el sometimiento incondicional a Roma. ${ }^{27}$

Los jóvenes fueron los más sensible y afectados por este fuego cruzado de las expectativas despertadas por el Concilio y de la misma cultura de protesta, rebeldía, exaltación de la libertad personal y explosión de los derechos que se puso en marcha en el mundo occidental desde la revolución contracultural de los 60, (la Segunda Reforma, así la apellidó Paul Goodman, aludiendo al libre examen de la Primera). Ahora, en esta nueva generación, la pasión indomable por la libertad que atraviesa a todo el mundo impulsa a los jóvenes católicos a reclamar una Iglesia más libre, más liberada y más liberadora. La mayor parte "pasa" serenamente de una Iglesia que no se presenta- no sabe o no quiere - como la "Patria de las Libertades" que alguna vez pudo soñarse. Una Iglesia más libre ante las tradiciones y" reliquias" del pasado, más liberada de compromisos con los poderes políticos y económicos, $\mathrm{y}$, sobre todo, más liberadora, menos aficionada a imponer normas y prohibiciones a propósito de tantas cosas, a decir NO.

27 José M. Castillo: La Iglesia que quiso el Concilio, Madrid, PPC, 2002, $2^{\mathrm{a}}$ ed., págs. 137-42 


\section{EXPECTATIVAS Y ESPERANZAS PARA LA VIDA CONSA- GRADA}

Abundan las antinomias y los obstáculos que frenan en no pocos jóvenes una respuesta acogedora al llamamiento a una vida consagrada, a la liminidad, rupturas y exigencias de la misma. Pero no puede dudarse de que hay llamamientos y hay respuestas. De los primeros nos han dejado una clara prueba los datos de "Jóvenes españoles 99", mencionados al comienzo de este artículo. Un breve recuerdo solamente:

Un 6,4\% de los jóvenes españoles entre 15 y 24 años declararon que "habían pensado en la vida religiosa o sacerdotal como una posibilidad de vida". De ese $6,4 \%$ lo habían pensado de forma ocasional el $5,9 \%$, lo que en números absolutos equivale a 360.000 "candidatos posibles y remotos"; lo habían considerado "a menudo" el 0,5, es decir, 30.772 "candidatos probables y más próximos".

Por si sirve de algún consuelo: no es la vida consagrada la única perjudicada por el "avance del desierto" en el terreno de los compromisos. Los jóvenes manifiestan de muchas formas su alergia y rechazo a comprometerse en proyectos de vida sólido, estables y permanentes. Lo hacen en todos los terrenos: la defensa del país, el asociacionismo, la pertenencia sindical o política, el matrimonio. El desplome de "lealtades" en la sociedad española ha sido estremecedor. Como en tantas otras sociedades. Afirma rotundamente Demarchi:

"No se ha podido comprobar que haya hoy menos interés por la vocación a la perfección moral y a la caridad total, pero si debe registrarse una fuerte disminución de la predisposición hacia los compromisos prolongados y definitivos (...) que exigen una fe de intensidad heroica en la providencia divina, un creer en la paternidad divina contra toda prueba evidente. Es difícil que la crisis vocacional se resuelva en poco tiempo. Basta con observar qué débiles son los vínculos matrimoniales, qué vacios están los ideales profesionales, qué solo está el hombre en la sociedad industrial..."28.

28 Franco Demarchi: "Ordini religiosi”, en Nuovo Dizionario di sociología”, Milán, Paolinas 1987. 
Se plantea aquí un serio interrogante: ¿cuáles son las formas de vida consagrada que ahora muestran un crecimiento excepcional, de difícil comprensión en el "desierto" actual de aspirantes a la VC? Un reportaje elaborado por el suplemento semanal de "La Razón" ofrece el siguiente panorama: 29

\begin{tabular}{|l|c|c|}
\hline \multicolumn{2}{|c|}{$\begin{array}{c}\text { EVOLUCION NEGATIVA DE LAS CONGREGACIONES } \\
\text { RELIGIOSAS MÁS NUMEROSAS, ENTRE 1974 Y 1999 }\end{array}$} \\
\hline Congregaciones & $\begin{array}{c}\text { Número miembros } \\
\text { en 1999 }\end{array}$ & $\begin{array}{c}\text { Disminución } \\
\text { entre 1974 y 1999 }\end{array}$ \\
\hline Hijas de la Caridad & 25.533 & $-38 \%$ \\
\hline Jesuitas & 22.227 & $-29 \%$ \\
\hline Franciscanos & 17.615 & $-24 \%$ \\
\hline Capuchinos & 11.373 & $-16 \%$ \\
\hline Benedictinos & 8.589 & $-20 \%$ \\
\hline Dominicos & 6.188 & $-23 \%$ \\
\hline Maristas & 4.996 & $-38 \%$ \\
\hline Claretianos & 2.894 & $-3 \%$ \\
\hline Agustinos & 2.793 & $-27 \%$ \\
\hline Hermanitas de los Ancianos & 2.715 & $-7 \%$ \\
\hline Vedruna & 2.424 & $-25 \%$ \\
\hline Compañía de María & 1.947 & $-37 \%$ \\
\hline Hijas del Corazón de María & 1.900 & $-52 \%$ \\
\hline
\end{tabular}

Fuente: Anuarios Pontificios, Guía de las Comunidades Femeninas en España.

Y Guía de las Comunidades Religiosas en España ( $L a$ Razón, 18-XII, 2002).

Nota: Las Congregaciones subrayadas son femeninas.

29 "Las Congregaciones religiosas han perdido más de 50.000 sacerdotes desde el Vaticano II", publicado en La Razón, suplemento semanal, 18-XII-2002. 
Nos interesan también las Congregaciones y organizaciones religiosas que han experimentado un crecimiento en el mismo período considerado en la Tabla anterior. Porque el contraste es de una magnitud que llama vivamente la atención, y que invita a profundizar en las diferencias de "oferta de vida consagrada" que se manifiestan hoy en la Iglesia Católica. Aunque no todo depende de la oferta institucional, hay otras razones y motivos, como luego se verá.

Los grupos que han experimentado un crecimiento considerable con los siguientes:

\begin{tabular}{|l|c|c|}
\hline \multicolumn{3}{|c|}{ CONGREGACIONES Y GRUPOS RELIGIOSOS QUE HAN } \\
EVOLUCIONADO POSITIVAMENTE ENTRE 1974 Y 1999 \\
\hline Congregaciones y Grupos & $\begin{array}{c}\text { Número miembros } \\
1999\end{array}$ & $\begin{array}{c}\text { Crecimiento } \\
1974 \text { y 1999 }\end{array}$ \\
\hline Salesianas & 16.231 & $+31 \%$ \\
\hline Misioneras de la Caridad & 4.629 & $+463 \%$ \\
\hline Combonianos & 1.988 & $+13 \%$ \\
\hline Carmelitas Misioneras & 1.926 & $+2 \%$ \\
\hline Legionarios de Cristo & 1.378 & $+94 \%$ \\
\hline Javerianos & 899 & $+5 \%$ \\
\hline Hermanas de la Cruz & 698 & $+3 \%$ \\
\hline Claretianas & 571 & $+15 \%$ \\
\hline Obra Misionera de Jesús & 213 & $+66 \%$ \\
\hline María & 134 & $+191 \%$ \\
\hline Verbum Dei & & +3 \\
\hline
\end{tabular}

Fuente: la misma de la tabla anterior.

Nota: Las congregaciones subrayadas son femeninas.

No es intención de este artículo analizar las causas y los factores que han influido en el declive vocacional de las últimas décadas, tema sobradamente estudiado, aunque de forma poco satisfactoria, por la Sociología de la Vida Religiosa, que, en España, se ha limitado, con excepciones, a divulgar tablas estadísticas de dudosa utilidad y escaso esfuerzo interpretativo. Pero parece aconsejable trazar aquí un sencillo esquema de aquellas causas y factores, a fin de situar adecuadamente la última reflexión de este artículo. 


\section{Perspectiva sociológica de las causas del declive de las vocaciones a la $\mathrm{VC}$}

\section{Causas socio-estructurales}

- Descenso demográfico en países occidentales, lo que ha reducido el número de posibles candidatos.

- Estructura ocupacional más abierta, con gran participación de la mujer, y disminución consiguiente del atractivo de la $\mathrm{VC}$ como "salida" ocupacional.

- Nuevos modelos de familia: "recicladas", monoparentales y reducidas, lo que ha favorecido el aumento de chicos con problemas por una socialización difícil.

- Estado del Bienestar y Misionarado cívico (ONG), lo que implica más opciones abiertas de trabajar para el bienestar de los demás.

- Secularización como emancipación de instituciones sociales, que ha privado a la Religión de su preeminencia y su función rectora de la sociedad.

\section{Causas culturales}

- Secularización como racionalización e incredulidad, con efectos negativos en los niveles de religiosidad.

- Cultura de la diversión frente a la Cultura del deber, junto con él.

- Valor primordial de la autonomía personal, junto con él.

- Individualismo expresivo-hedonista: estos tres factores han tenido un fuerte efecto disuasor en las eventuales respuestas a un llamamiento a la VC.

\section{Causas eclesiales}

- Status del sacerdote, religioso y religiosa en declive en las sociedades postindustriales.

- Frustración de las expectativas de reforma de la Iglesia.

- Imagen pública poco simpática de la Iglesia.

\section{Causas institucionales}

- Inmovilismo reformista de algunas Ordenes y Congregaciones religiosas, con impacto negativo en la estima juvenil.

- Reformas rupturistas en algunas congregaciones o grupos religiosos, con efectos desestabilizadores y numerosos abandonos.

- Ofertas de VC deficientes, de escasa atracción para los jóvenes insertos en un estilo de vida orientado al éxito socioeconómico, la novedad, la apertura... 
A lo largo del siglo pasado se pensó sobre todo en la secularización como la causa por excelencia del aumento de la incredulidad y desafección religiosa en el pueblo cristiano y del declive de las vocaciones sacerdotales y religiosas. Parecía que la secularización lo explicaba todo, como anteriormente lo explicaba todo la industrialización, y hoy día parece explicarlo todo la postmodernidad. Pero recientemente la hipótesis de la secularización ha sido reemplazada, o por mejor decir, completada, por la hipótesis del individualismo ${ }^{30}$, al tiempo que se iba abriendo paso entre muchos estudiosos de la religión el llamado Nuevo Paradigma, que se centra en el problema del nivel de excelencia de la oferta. ${ }^{31}$ Es pertinente, por tanto, breve comentario sobre la hipótesis del Individualismo y del llamado "Nuevo Paradigma".

Los datos de un país muy descristianizado, como punto de partida. En 1999 sólo el 19\% de los holandeses se consideraban católicos, otro $15 \%$ protestantes (un $7 \%$ neocalvinistas y un $8 \%$ de la Iglesia Reformada), y una fracción residual, de otros grupos religiosos. Ha sido el declive más rápido y espectacular entre todos los países de tradición Cristiana. Pero al mismo tiempo no pocos sociólogos hablan del aumento de la religiosidad en Holanda, "verdadero jardín experimental de religiones" (Jansenn). Entre ellas, de manera preeminente, el movimiento New Age (Nueva Era).

¿Cómo se puede explicar esta situación, esta paradoja? Frente a la hipótesis de la racionalización, (o secularización), los autores del trabajo en cuestión afirman que la racionalización no se ha extendido en Occidente como se pensó, que el conflicto Ciencia-Religión ha perdido gran parte de su histórica importancia, y que el auge de la New Age significa que la fe en la ciencia y en la tecnología no se opone a la fe religiosa. El crecimiento de la New Age como forma actual de religión no se compadece con la hipótesis de la racionalización. Hay que buscar una hipótesis alternativa: la de la Individualización.

30 Dick Houtman y Peter Mascini: "Why Do Churches Become Empty, While New Age Grows? Secularization and Religious Change in the Netherlands", en Journal for the Scientific Study of Religión, 41:3, (2002), pp. 455-473.

${ }^{31}$ Lo ha expuesto sucintamente Lluis Oviedo en un excelente trabajo, aún no publicado: "Religious Virtuosi at the Proof of Time: Testing Survival Strategies by Catholic Religious Orders, "paper" para la Reunión Anual de de la Sociedad para el Estudio Científico de la Religión, Salt Lake City, 1-3 noviembre 2002). 
La hipótesis de la Individualización, en una línea próxima a la "Religión invisible" de Luckmann, sostiene que el Cristianismo ha cedido su puesto en nuestro tiempo a una forma de religión más o menos invisible caracterizada por el énfasis en la auto expresión, la auto realización y la libertad individual. El mismo Luckmann piensa que la forma preeminente de religión invisible es hoy la New Age, en la que el desarrollo espiritual del individuo es el tema dominante y brillan por su ausencia una organización estable, dogmas sacralizados, un sistema de reclutamiento de los miembros y un sistema disciplinar. Heelas (1966) explica la popularidad creciente de la New Age por su plena coincidencia con el clima espiritual que hoy respiramos. Los miembros de la New Age, nuevos gnósticos, rechazan todo tipo de tradición externa y de autoridad, consideran al Yo como la autoridad moral primordial, y se guían por la intuición personal, la iluminación y la voz interior a la hora de emitir juicios, tomar decisiones y realizar opciones. Conectan así perfectamente con el espíritu de nuestra época, marcado por el individualismo moral, la postradicionalización y el rechazo de las autoridades.

El nuevo paradigma toma una dirección distinta pero no contradictoria a la hora de indagar la causa fundamental del declive religioso de nuestro tiempo. El punto de partida de la nueva hipótesis es la responsabilidad de los factores internos o de la oferta en la dinámica religiosa. En los últimos años se ha intentado aplicar la "teoría de la oferta y la demanda religiosa" a grupos o sectores del espectro religioso de mayor intensidad religiosa, caracterizados por su alto nivel de tensión o contraste con su entorno. Es decir, los "religious virtuosi", los hombres y mujeres que han elegido la vida consagrada.

En su busca de factores que pueden incluir en la dinámica vocacional de su Orden (Franciscanos), el estudio de Lluis Oviedo utiliza seis variables relacionadas con diferentes argumentos del Nuevo Paradigma: 32

1. Severidad (strictness), en el sentido acuñado por Stark, Iannaconne y Finke: ceteris paribus, un mayor nivel de severidad, hasta

${ }^{32}$ Lluis Oviedo, op. cit., pág. 2. 
un cierto límite, puede contribuir a mayores oportunidades de supervivencia del grupo.

2. Identidad y sentido de pertenencia: los grupos religiosos con mayores niveles de identidad y autoestima pueden encajar mejor en un entorno (en un mercado espiritual) libre y competitivo. Así lo sostienen Stark, Iannaconne y Wittberg.

3. Certeza doctrinal: se ha demostrado que en tiempos de crisis cultural sólo los grupos que mantienen niveles más altos de firmeza doctrinal resisten las convulsiones (Dawson).

4. Orientación específica de actividades: $M$. Chaves ha defendido la tesis de que los grupos religiosos que actúan más allá del ámbito dominado por la autoridad religiosa caen en la dinámica de una "secularización interna", y, por el contrario, los grupos más encaminados a actividades religiosas específicas deben ser más capaces de crecer.

5. Compromiso y movilización: se ha recalcado que la participación depende de los niveles de compromiso o de la "expansividad" del grupo religioso, expresada en su tendencia a dedicarse a actividades de reclutamiento (Dougherty).

6. Estilos de oración: Stark y Finke han mostrado que las vocaciones religiosas en el mundo católico crecen normalmente cuando la institución es capaz de realizar un "retorno selectivo e innovador" a la tradición.

Dilani había insistido en tres rasgos cuyo atractivo para los jóvenes aparece corroborado por un estudio cualitativo de los nuevos grupos eclesiales que triunfan ${ }^{33}$ : Legionarios de Cristo, Oblatos de la Virgen María, Opus Dei, Misioneras de la Madre Teresa, Comunión y Liberación, Hijas de San Pablo...

- En primer lugar: "Objetivos explícitamente religiosos que colmen el vacío interior, y la búsqueda de un mensaje claro y explícito sobre los grandes sentidos: vida, muerte y resurrección. (Los nuevos grupos religiosos) hablan así con sencillez y facilidad de la salvación, de la voluntad de Dios, de la santidad, de la vocación como llamamiento divino, de la necesidad de comunidad, etc.

33 Albert Dilani "Religious vocations. New Signs of the Times", en Review for Religious, sep.-oct. 1993, p. 745-63. 
- En segundo lugar, una intensa vida de comunidad y solidaridad como reacción a la excesiva fragmentación de la vida en la sociedad actual, al individualismo y a la atomización social.

- En tercer lugar, pasión por una evangelización explícita y abierta al mundo, para la que están dispuestos a enfrentarse en obediencia a la precariedad de la vida en misión en cualquier parte del orbe.

Witteberg enumera por su parte una breve serie de rasgos de las "empresas religiosas con éxito vocacional: su oferta vocacional es "nueva", son exigentes y tradicionales en su doctrina pero innovadores en sus métodos, sus miembros están estrechamente unidos entre sí y mantienen esta unión y cercanía por medio de prácticas comunitarias o por una forma estructurada de vida mediante una regla; su piedad es sencilla y crítica, y su vida espiritual tiende a sustentarse en la reflexión comunitaria y en la participación en común de experiencias personales nacidas de la lectura de la Palabra de Dios: fuerte espíritu de pobreza entendida como renuncia personal y como un trabajo exclusivo para los pobres. ${ }^{34}$

¿Se agotan en esta enumeración de Dilani y Wittberg las señas de identidad de grupos religiosos destacados por una oferta de VC que los hace exitoso y competitivo? Con otras palabras, excelente? ${ }^{35}$ Desde luego que no. Hace ya bastantes años Dean Kelly había elaborado una lista de cualidades que explicaban la fortaleza y crecimiento de alas que llamaba "Iglesias fuertes" (Pentecostales, Baptistas, Evangélicos...). Entre esas cualidades o rasgos de "excelencia" llaman la atención algunas perfectamente aplicables a las diversas modalidades de vida consagrada presentes en la Iglesia Católica: el liderazgo carismático, "la seriedad, rigor y severidad", y la participación, el compartir en comunidad las convicciones y experiencias espirituales. ${ }^{36}$ Otros autores, en el pasado y en el presente, han insistido en la nota de novedad

34 Patricia Wittberg: The Rise and Fall of Catholic Religious Orders, New York, State University of New York Press, 1994, págs. 269-70.

35 Empleo el término "excelencia" en el sentido que le asigna la moderna Teoría de la Contingencia en la sociología de las organizaciones: el ajuste y equilibrio entre el entorno organizacional, la estructura de la organización, sus recursos tecnológicos y humanos, actuales y potenciales, las demandas del mercado, etc. Las organizaciones empresariales no han recibido un "carisma -jalgunos famosos grandes empresarios norteamericanos están convencidos de que sí lo han recibido!- pero el carisma como don divino sí pertenece por derecho propio a las Órdenes, Congregaciones y otros grupos religiosos. 
y juventud a la que se refiere Wittberg, en línea con la Exhortación Apostólica "Vita consecrata" de Juan Pablo II: "El Espíritu Santo, admirable artífice de la variedad de los carismas, ha suscitado en nuestro tiempo nuevas formas de vida consagrada (...) en las que la perenne juventud de la Iglesia continúa manifestándose también hoy."37

El aviso de Finke en un trabajo publicado en 1997 es digno de atención aunque pueda ser duro de aceptar para algunos. El autor utiliza los datos del estudio sociológico de 1993 de CARA para verificar su hipótesis inicial: los grupos aumentan su "producción de bienes colectivos" o recompensas sociales y religiosas para sus miembros (como el compromiso, el fervor, las experiencias religiosas, el apoyo y calidez de la comunidad, los rituales religiosos, los ejercicios espirituales, la oración), si limitan las actividades externas (outgroup) de sus miembros y les exigen que sacrifiquen sus oportunidades profesionales, que se consagren a la misión del grupo y que reserven sus relaciones sociales más intensas para los miembros de su grupo. Así aumenta su dependencia del grupo, aumenta el coste de la membrecía, de pertenecer a ese grupo, pero, paradójicamente, aumenta también el atractivo del grupo y la demanda de nuevos candidatos. Finke concluye su análisis ${ }^{38}$ dando por verificada su provocativa hipótesis, fundada no sólo en el estudio de CARA sino en la literatura sociológica sobre el tema de las comunas y pequeñas comunidades voluntarias: las limitaciones analizadas, el elevado coste de la pertenencia no retrae a los jóvenes, sino que, por el contrario, los atrae. Habrá, sin duda, otros factores de atracción, pero éste parece ser un rasgo valioso de la "oferta de VC".

La limitación de las actividades externas de los miembros del grupo, la dedicación estricta a la misión comunitaria del grupo, el rechazo de la dispersión de la actividad del grupo, y los cambios restrictivos en el estilo de vida requeridos por esas limitaciones es llama-

${ }^{36}$ Dean Kelly: "Why Conservative Churches Are Still Growing ", en Journal for the Scientific Study of Religión, 17/2, junio 1978, págs. 165-73.

37 Juan Pablo II: La Vida Consagrada. Vita consecrata. Exhortación apostólica de S.S. Juan Pablo II, Madrid, San Pablo, 1997, págs. 18-19.

38 Roger Finke:" An Orderly Return to Tradition": Explaining the Recruitment of Members into Catholic Religious Orders", en Journal for the Scientific Study of Religión, $36 / 2$, junio 1997 , págs. 218-206. El estudio cuyos datos fueron utilizados para verificar la hipótesis fue realizado en 1993 por el "Center for Applied Research in the Apostolate (CARA) sobre 2.136 religiosas de 531 congregaciones religiosas, en Estados Unidos. 
da por Finke "strictness, seriousness o distinctiveness", inspirándose en el trabajo de Kelly, ya mencionado. Sospecho que incluso la flexibilidad del lenguaje anglosajón para designar nuevas realidades encuentra aquí dificultades. Habría que emplear en español un término compuesto, que sonara algo así como "misión intracomunitaria". Quizás, simplemente y para simplificar: "intracomunidad"...Turcotte ha vuelto sobre el tema en un trabajo reciente: el término clave es consistencia, entendida como "apoyo de una comunidad comprometida, firme creencia en el valor de las renuncias juzgadas pertinentes, reconocimiento externo de prácticas diferentes, sobre todo en relación con el ascetismo y la virtud, restricción de actividades externas, participación activa en el grupo, y distinción en relación con la vida secular'".39

Antes de desarrollar algunos elementos constitutivos de una "oferta excelente" de VC, hay que tener muy en cuenta un aspecto fundamental de la demanda: más que las necesidades institucionales de la congregación hay que tener en cuenta las necesidades de los jóvenes, como recuerda un experto en la vida religiosa: "la propuesta que se haga más que tener en cuenta las necesidades o aspiraciones de la vida religiosa o de los Institutos, será una respuesta a las verdaderas necesidades de los jóvenes. Para ello está respuesta incluirá: espiritualidad, solidaridad y servicio". ${ }^{40}$ Añado: además de las "verdaderas necesidades" de los jóvenes, hay tener en cuenta los obstáculos o antinomias a la VC que se han visto en la primera parte de este artículo.

Entre los elementos concretos de la "oferta excelente" de Vida Consagrada que pueden responder a la demanda juvenil y estimularla, hay que señalar las siguientes, sin pretensión alguna de agotar el tema.

- En primer lugar, la oferta de una UTOPÍA, un sueño, un hogar del espíritu, un "espacio sagrado y tiempo sagrado", una estructura liberadora de vida, comunicación y participación intergeneracional. ${ }^{41} \mathrm{El}$ concepto de liminalidad, ya mencionado, amplía este primer rasgo de la oferta. La VC potencia la autenticidad de la

39 Paul-André Turcotte: "The Religius Order as a Cognitive Minority in the Church and in the Society", en Social Compass, 48/2, 01, pág. 187.

40 José María Arnaiz: "Una vida religiosa para los jóvenes...", en Vida Nueva, N. 2085, pág.. IX del folleto "con El".

${ }^{41}$ Mary Jonson: "Religious Life in the USA: Community as a Key Bridge to Young Adults, en Social Compass", 48/2, 2001, pág. 234. 
persona humana y las personas que "la viven de manera original y relevante actúan como iniciadores y modelos para los demás. Su experiencia religiosa y su función social les lleva a poner en evidencia, y si es necesario, en estado de contraste, determinados valores de la persona humana, como la simplicidad y la austeridad, la centralidad de la relación y el encuentro con 'lo santo', la misericordia y la no violencia, la moderación y el recogimiento, la armonía con el cosmos y la vida de comunidad. Por eso muestran una admirable libertad con relación a las instituciones y las relativizan, a veces ostensiblemente". ${ }^{42}$ La mayor parte de los valores que hermosean y hacen tan atractivos los Movimientos Sociales que fascinan hoy a tantos jóvenes, empezando por el ecologismo y acabando por el Pacifismo, están presentes en la utopía de la VC, y de una forma radical. En este sentido y sin olvidar su carácter sobrenatural, los hombres de la VC tienen como objetivo "anunciar la Buena Nueva a ese mundo gris del futuro y trazar los signos y las medidas de un nuevo humanismo cristiano en un amplio gesto histórico".43

- En segundo lugar el profetismo: "Alguien es llamado para una misión, para un servicio en el plan salvífico y liberador de Dios. Es verdad que la misión puede ir desde el silencio simbólico o la mera presencia testimonial hasta la denuncia profética y la militancia arriesgada", recuerda Martínez Díez, quien precisa así su pensamiento: los dos rasgos esenciales de la misión profética son "el anuncio de la Palabra y la práctica de signos liberadores. El profeta ha recibido la Palabra de Dios y está obligado a proclamarla, anunciando liberación y denunciando la opresión. Propone al pueblo un futuro alternativo frente a un presente de pecado y de opresión. Abre los ojos a los ciegos para que reaccionen frente a un orden establecido que pretende ocultar el pecado y la opresión". ${ }^{44}$ La conciencia del desorden establecido y de la urgencia de

42 José Cristo García Paredes, 10 palabras sobre vida consagrada, op. cit., pág. 338-39.

43 José O. Zöller: El ocaso del 'señor'cura, Bilbao, Desclée de Brouwer, 1970, pág. 162.

44 Felicísimo Martínez Díez: Refundar la vida religiosa. Vida carismática y misión profética, $3^{\text {a }}$ ed., Madrid, San Pablo, 1996, págs. 273 y 291. 
una protesta radical están muy vivas en la generación joven, como lo han probado hasta la saciedad los movimientos antisistema y antiglobalización. Como sucede muy frecuentemente, se ha apoderado de ellos la izquierda. Los jóvenes no sienten que la Iglesia tenga una respuesta para los grandes problemas que más les preocupan a ellos: el paro, el racismo, la falta de futuro, la explotación, la pobreza, la marginación... Muchos abrirían los ojos, con absoluta incredulidad, si se les dijera que la VC tiene una función profética, una misión "simbólico-política" y "político-mística", como muy bien explica el autor citado.

- En tercer lugar, una oferta de libertad, difícil de entender, pero de absoluta realidad. Se refiere a ella Luz Galván en unas luminosas páginas de Vida Nueva cuando afirma que "los votos que hacemos nos conducen a la libertad" 45 , algo "incomprensible para los jóvenes". Los votos serían" actitudes críticas y liberadoras, implican voluntad de solidarizarse con el mundo y la creación, y a la vez, valentía para ser una contracultura."La VC es una invitación y una práctica y un programa para desalienarse. ${ }^{46}$ Los jóvenes de la revolución contracultural del 68 hablaban de "desprogramarse", y su objetivo sigue siendo hoy perfectamente válido. Y los jóvenes más lúcidos de la generación actual perciben igualmente la alienación en la que viven, sobre todo a través del consumo, aunque ya no hablen de desprogramación.

- En cuarto lugar, la solidaridad, valor difícil pero que forma parte de manera destacada del imaginario juvenil. Un $12 \%$ de los jóvenes españoles de 1999, en la tipología de Javier Elzo, pueden ser calificados de altruistas comprometidos, abiertos totalmente a la colaboración con una ONG, y en el grupo más numeroso de la tipología, el de los institucionales ilustrados, aunque menos activos en tareas altruistas que los jóvenes del grupo anterior, a un $62 \%$ les gustaría trabajar en asociaciones de voluntariado. Repre-

${ }^{45} \mathrm{M}^{\mathrm{a}}$ Luz Galván: "Europa, retos a la vida religiosa", en Vida Nueva, N. 2.053, 10 y 17 agosto de 1996, pág. IX.

${ }^{46}$ M. Díez Presa: Antropología de la vida religiosa, Madrid, Instituto Teológico de vida religiosa, 1984, págs. 153 ss. 
sentan un $30 \%$ del total. ${ }^{47}$ Aún descontando la presencia de lo que podrían denominarse "valores fonéticos", más presentes en la cómoda región de los buenos deseos que en la dura realidad, la vigencia del valor solidaridad es evidente.

- En quinto lugar, la comunidad cálida, la VC como "signum fraternitatis", como figura en la Exhortación Apostólica de Juan Pablo II "Vita consecrata". En su estudio de 1974 sobre los abandonos de la vida religiosa Gerardo Pastor citaba los problemas de la vida intracomunitaria como el segundo en importancia, el primero entre las religiosas, después de los problemas de sexualidad, aunque ambos potenciados por los cambios institucionales que en ese momento estaban experimentando la mayor parte de las Congregaciones religiosas. ${ }^{48}$ Ahora, en un momento en el que la sociedad occidental parece ahíta de tanto individualismo y narcisismo, y nostálgica de las "pequeñas comunidades", como han certificado sociólogos del renombre de Bellah, Putnam, y Etzioni, una oferta excelente de VC puede contar con este aliado, insospechado hace sólo unos años. Y en la Iglesia Católica la querencia de comunidades cálidas es ya un punto de confluencia de numerosos estudios, reformas y experiencias. Hervieu-Léger lo ponía de relieve al tratar del poder del carisma en el despliegue de la nebulosa de grupos y comunidades de inspiración cristiana que, a su juicio, prefiguraban una "religión de comunidades emocionales", fundadas sobre la dinámica interna de la emoción que resulta de la intensidad afectiva del compromiso comunitario de cada uno de sus miembros. ${ }^{49} \mathrm{La}$ VC, "experta en comunión y solidaridad", tiene como misión profética no sólo la denuncia y la protesta sino, sobre todo y ante todo, ofrecer una experiencia de fraternidad, una fraternidad que genera fraternidad, porque el problema del mundo" no era la falta de bienes; ni los espirituales ni los mate-

47 Javier Elzo: "Ensayo de una tipología de los jóvenes españoles basada en sus sistemas de valores", en Jóvenes españoles 99, Madrid, Fundación Santa María, 1999, págs. 25-31.

48 Gerardo Pastor: Análisis de contenido en los casos de abandono de la vida religiosa, Madrid, Instituto Teológico de Vida Religiosa, 1974, págs. 354-57.

${ }^{49}$ Danièle Hervieu-Léger: Vers un nouveau Christianisme?, Paris, Cerf, 1986, págs. $341-54$. 
riales escaseaban. Faltaba la comunión. Se necesitaban células de comunión que reprodujeran y sanearan el cuerpo social (...) Eran más urgentes los signos de comunión que los servicios". 50

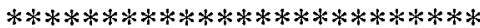

Para los jóvenes que han acariciado en algún momento de sus vidas un proyecto de $\mathrm{VC}$-el $6,1 \%$ de la actual generación, como se vio- no hay ya perspectivas de poder, status, seguridad material, liderazgo temporal o "carrera" en su eventual futuro de sacerdote o religiosa y religiosa. La secularización de la sociedad, la evolución de la Iglesia postconciliar, la multiplicación de las oportunidades ocupacionales, sobre todo para las mujeres ${ }^{51}$, la profundización teológica de la vida religiosa, la cultura juvenil de nuestro tiempo, y, en los países occidentales, la misma prosperidad económica, han barrido definitivamente aquellos "objetivos" o "recompensas", pretendidos o no, que acompañaban a bastantes formas de VC. Peligrosos "compañeros de camino"... La revolución ha sido intransigente. Ha sido una revolución que merece el agradecimiento entusiasta de todos los verdaderamente creyentes.

En su lugar, las nuevas ofertas excelentes de VC pueden ofrecer a los jóvenes una utopía radicalmente humanista y cristiana, una misión profética de denuncia y de protesta, una vida de libertad personal enraizada en unos votos liberadores para el Reino, un ejercicio comprometido de solidaridad y amor, y una comunidad cálida y fraterna. Sólo eso. Todo eso.

50 José M. Arnaiz:" Una nueva forma de vida religiosa", en CONFER, N. 130, abriljunio 1995, págs. 321-322. El autor se sitúa imaginativamente en el año 2095, lo que explica su afirmación de que no eran los bienes espirituales ni los materiales los que faltaban...Dios le oiga.

51 El cambio de estructuras ocupacionales y el aumento de oportunidades de empleo para la mujer se correlacionan positivamente con el declive de las congregaciones femeninas en todo el mundo, como ha demostrado un estudio macro sociológico de Helen Rose Ebaugh: "The Growth and Decline of Catholic Religious Orders of Women Worldwide: The Impact of Women's Opportunity Structures", en Journal for the Scientific Study of Religion, 32/1, marzo 1993, págs. 68-75. 